\title{
Tunneling and Propping: A Justification for Pyramidal Ownership*
}

\author{
Yohanes E. Riyanto ${ }^{\dagger}$ \\ Linda A. Toolsema ${ }^{\ddagger}$ \\ National University of Singapore \\ University of Groningen
}

February 12, 2004

\begin{abstract}
This paper presents a formal model of tunneling and propping in a pyramidal ownership structure. Tunneling refers to controlling shareholders shifting funds from one firm to another in the same pyramid. Propping is tunneling that is done to save the receiving firm from bankruptcy. We compare the pyramidal ownership structure to the horizontal ownership structure, in which shifting funds between firms is not possible. We show that tunneling may justify the pyramidal structure only with myopic investors or in combination with propping.
\end{abstract}

Keywords: Tunneling; Propping; Pyramids; Ownership Structure; Business Groups.

JEL classification: G32, L22.

${ }^{*}$ This is a preliminary draft, please do not quote. The authors thank participants of seminars at the National University of Singapore and the University of Groningen for helpful discussion.

${ }^{\dagger}$ Department of Economics, National University of Singapore, AS2 1Arts Link, Singapore 117570. E-mail: ecsrye@nus.edu.sg.

$¥$ Department of Economics, University of Groningen, P.O.Box 800, 9700 AV Groningen, The Netherlands. E-mail: L.A.Toolsema@eco.rug.nl. 


\section{Introduction}

In their seminal study on the modern corporation, Berle and Means (1932) argue that one of the distinguishing characteristics of the modern corporation is the existence of separation between ownership and control. The owners or shareholders of firms rarely get involved in the firms' day-to-day activities. Instead, managers are in charge. These managers may have an incentive to pursue opportunistic behavior at the expense of shareholders. Evidently, this creates a conflict of interests between shareholders and managers. This conflict of interests has become the center of attention in many corporate governance studies. ${ }^{1}$

There is yet another important conflict of interests within firms. This involves the controlling shareholder versus minority shareholders. The controlling shareholder may pursue actions that benefit her, at the expense of minority shareholders. This conflict has recently received much attention in the corporate governance literature. This started with the publication of a seminal article by La Porta, Lopez-de-Silanes, and Shleifer (1999), which shows that firms often belong to a business group characterized by a complex ownership structure. These firms are controlled through a chain of companies, where the ultimate controlling shareholder is often a wealthy family. This structure is usually referred to as a pyramidal ownership structure. The ultimate controlling shareholder uses indirect ownership to exert control over firms that belong to the same pyramidal chain. This implies that she is able to maintain control with a relatively small fraction of cash flow rights, thus creating a separation between control rights and cash flow rights. ${ }^{2}$

\footnotetext{
${ }^{1}$ See Shleifer and Vishny (1997) for an excellent and comphrehensive survey on corporate governance.

${ }^{2}$ There are two other ways in which the controlling shareholder can create a separation between control rights and cash flow rights, without relying on the creation of a pyramidal ownership structure. First, by issuing dual class shares, i.e. shares with differential voting
} 
As an illustration, suppose that a controlling shareholder (say, a family) owns $50 \%$ of firm $A$, and firm $A$ owns $30 \%$ of firm $B$. In turn firm $B$ owns $40 \%$ of firm $C$. Suppose that these are all controlling shares ${ }^{3}$ then the family exerts control over firm $C$ with only $50 \% \times 30 \% \times 40 \%=6 \%$ of cash flow rights. ${ }^{4}$ There is a clear separation between voting or control rights and cash flow rights here. As a real world example, consider the Li Ka-shing conglomerate, the largest business group in Hong Kong. Li Ka-shing and family own $35 \%$ of Cheung Kong, which owns $34 \%$ of Hutchison Whampoa. In turn, Hutchison Whampoa owns $60 \%$ of Cavendish International that owns $34 \%$ of Hong Kong Electric. Li Ka-shing and family are the ultimate controlling shareholders of Hong Kong Electric with $34 \%$ of control rights but only $2.5 \%$ of cash flow rights. $^{5}$

The separation between control rights and cash flow rights in the pyramidal ownership structure gives incentives for self-dealing transactions. That is, the controlling shareholder may transfer resources from a firm in the pyramidal chain to herself or to another (often a higher-level) firm, at the expense of minority shareholders of the former firm. Examples include asset sales, transfer pricing contracts that benefit other firms in the pyramid, and simple cash appropriation. Such activities are known as tunneling in the literature. Clearly tunneling can be profitable to the entrepreneur or family at the top of the pyramid. As an example, suppose that a family owns $50 \%$ of firm $A$, and firm $A$ owns $50 \%$ of firm $B$. The family's cash flow rights are $50 \%$ in firm $A$ and $25 \%$ in firm $B$. We assume that the $50 \%$ share is a controlling share, so

rights. Second, by establishing cross ownership with other firms. We abstract from these issues.

${ }^{3}$ From empirical studies we know that a lower bound for controlling shares is somewhere around $10 \%$ or 20\%. See for instance La Porta, Lopez-de-Silanes, and Shleifer (1999), Claessens, Djankov and Lang (2000), and Lemmon and Lins (2003).

${ }^{4}$ This assumes that other shareholders only hold small fractions of ownership in the firms.

${ }^{5}$ See Claessens, Djankov, and Lang (2000, p. 97). 
firm $B$ is controlled by firm $A$, which is itself controlled by the family. Also, we assume for simplicity that funds are equally profitable in firms $A$ and $B$. Denote the cash flow of firm $i$ by $\pi_{i}, i=A, B$. If the family decides not to tunnel, she earns $0.5 \pi_{A}+0.25 \pi_{B}$. If instead the family tunnels some amount $S>0$ from firm $B$ to firm $A$, she earns $0.5\left(\pi_{A}+S\right)+0.25\left(\pi_{B}-S\right)$. The latter is higher for any $\pi_{B}$ than the former. Therefore, even if the per-dollar return of the funds is the same in the two firms, the family may have an incentive to tunnel. The reason is simply that the family has higher cash flow rights in the higher-level firm $A$, and therefore would prefer to shift firm $B$ 's cash flow to firm $A$ whenever this is possible. Clearly, this makes the minority shareholders of firm $B$ worse off.

A specific type of tunneling where the transfer of resources between firms occurs in case of financial distress and aims to save the receiving firm from bankruptcy is known as propping in the literature (Friedman, Johnson, and Mitton, 2003). With propping, funds may be transferred from a lower-level to a higher-level firm as with 'ordinary' tunneling, or in the opposite direction. In the latter case, it may be interpreted as 'reverse' tunneling. In the remainder of this paper we will use the term 'tunneling' with a narrow interpretation, which does not include transfers of funds to save a firm from bankruptcy, for which we will use the term 'propping'. Section 2 presents some real world examples of tunneling and propping.

Both tunneling and propping may often be illegal (Johnson et al., 2000; Friedman, Johnson, and Mitton, 2003). However, as Johnson et al. (2000) illustrate, in many countries minority shareholders are not well protected and tunneling (and/ or propping) between firms in the same group is often allowed by the courts. ${ }^{6}$ In this paper, we focus on 'legal' tunneling activities. ${ }^{7}$

\footnotetext{
${ }^{6}$ This holds in particular for (French) civil-law countries, as opposed to common-law countries (Johnson et al., 2000). See also our discussion in Section 2. For evidence of propping, see Friedman, Johnson, and Mitton (2003).

${ }^{7}$ The amount of funds tunneled can be interpreted as retained earnings, i.e. a part of
} 
We assume that tunneling from one firm to another firm in the same group is possible (at least to some extent), but we abstract from tunneling funds from a firm directly to the ultimate controlling shareholder. The latter would be similar to the family simply looting all the firm's cash flow to herself as the ultimate controlling shareholder rather than paying out dividends according to each investor's (including her own) cash flow rights. ${ }^{8}$ As a result, in this paper tunneling is only possible under a pyramidal structure but not a horizontal structure (with independent firms).

As we explained above, the ultimate controlling shareholder of a pyramidal structure may decide to tunnel since this increases her cash flow. This suggests that tunneling could be an explanation or justification for the pyramidal ownership structure. In this paper, we look at this issue by investigating the incentives of a family that owns and controls a firm $A$ to set up a new firm $B$ in a pyramidal structure. Thus, firm $B$ will be owned and controlled indirectly via firm $A$, rather than as an independent firm as in a horizontal structure. To do so, we present a formal model of tunneling and propping in a pyramidal ownership structure that explicitly incorporates the establishment of the lower-level firm $B$.

We show that indeed the possibility of tunneling and propping in the pyramidal ownership structure may be a justification for using this structure, i.e.

profits that is retained and reinvested. The net profits after subtracting retained earnings are then distributed to shareholders as dividends according to their cash flow rights. The amount of profits and retained earnings are observable to all investors, however minority investors have no control over retained earnings.

${ }^{8}$ Clearly such an act can be deemed as illegal, as it is hard to justify why the controlling family does not distribute dividends out of the company's profits. If the family argues that the absence of dividends is due to all available cash flows being retained and re-invested, investors would demand a disclosure of information on the use of these retained earnings. Such an act may likely lead to a court case when it is eventually discovered. A notorious recent example is the case of Parmalat, an Italian business group owned by Tanzi family (see The Economist, 2004). Its founder, Calisto Tanzi, personally squandered up to 800 million euro from the group. To cover up this act, he forged a bank document showing that one of Parmalat subsidiaries had deposits amounted to 4 billion euro. 
for preferring it over the horizontal structure where it is not possible to shift funds from one firm to another. However, when propping is not possible, for example because we know that firm $B$ will never be in a financial distress or propping is illegal and can be very easily verified by the court, the family will never strictly prefer the pyramidal structure over the horizontal structure. This is because outside (minority) investors foresee that there will be tunneling in the pyramid and accordingly adjust their willingness to pay for firm $B$ 's shares at its establishment - unless when they are myopic and do not realize the (full extent of) tunneling. With rational investors, however, when there is some probability of financial distress, outside investors realize that in the pyramidal structure the controlling shareholder may prop-up firm $B$. This is a clear benefit from the pyramidal structure, which raises their willingness to pay for $B$ 's shares. Thus, in this case, the family may be better off adopting the pyramidal structure.

There are some other papers which provide formal models of tunneling and propping, for example Obata (2001) and Friedman, Johnson, and Mitton (2003). However, these authors do not model explicitly the establishment of firm $B$. Although they argue that tunneling (or propping) may benefit the ultimate controlling shareholder, and thus suggest that this may be a reason to set up firms in a pyramidal structure, they do not formally analyze this question. The present paper adds to this literature by showing that tunneling alone cannot justify the pyramidal structure (unless investors are myopic), whereas it can when it is combined with propping.

The remainder of this paper is structured as follows. We first discuss some related literature in Section 2. Section 3 describes a simple benchmark model of tunneling. In this section we assume that the pyramidal structure is already in place, and we analyze the family's decision on how much to tunnel. This benchmark model enables us to obtain a better understanding of tunneling and its relationship with the quality of the legal protection of minority share- 
holders. Section 4 presents the setup of the general model. Here we extend our analysis to cover both tunneling and propping. In Section 5 we solve the model and derive the family's payoffs under the two ownership structures. In Section 6 we compare these payoffs and show that tunneling alone will not lead to the emergence of pyramidal ownership structure, but in combination with either myopic investors or propping, it may. Section 7 concludes.

\section{Related literature}

As we mentioned above, La Porta, Lopez-de-Silanes, and Shleifer (1999) have shown that firms are often part of a business group with a pyramidal ownership structure. They studied the 20 largest publicly owned firms in each of the 27 wealthiest countries, and concluded that controlling shareholders often have cash flow rights that are much smaller than their control rights, mostly due to pyramidal ownership. Similarly, Claessens, Djankov, and Lang (2000) tracked the ultimate owners of 2980 listed firms in nine East Asian countries. They found that the pyramidal ownership structure is common in these countries ( $38.7 \%$ of the firms are controlled using a pyramidal structure) and that there is a substantial deviation between control rights and cash flow rights.

Pyramidal ownership structures may lead to tunneling and propping. Several authors present real world examples of legal tunneling (see in particular Johnson et al., 2000). We mention one example here, that is the case of Flambo and Barro. Barro, a Belgian company, accused Flambo, its French controlling shareholder, of stripping Barro of its assets and trying to pledge the company as a collateral to guarantee Flambo's debt (Johnson et al., 2000). The court decided in favor of Flambo on the basis that Flambo's conduct was in conformance with the interests of the business group as a whole. The court argued that it is legal for a subsidiary to help its parent 
company out as long as this does not jeopardize the financial condition of the subsidiary.

As an example of propping, consider the case of the Salim group, one of the biggest business groups in Indonesia. The Salim group injected funds from a publicly listed Hong Kong company into a publicly listed Indonesian company during the financial crisis (see Friedman, Johnson, and Mitton, 2003). Similarly, LG Securities, one of the most profitable firms in the LG Group, acquired the money-losing debt-ridden LG Merchant Bank, also part of the LG Group. This led to a dramatic drop in LG Securities' share value (Bae, Kang, and Kim, 2002).

Whether or not tunneling is legal, it is often hard to verify. Bertrand, Mehta, and Mullainathan (2002) devise an indirect approach to measure the extent of tunneling by looking at the cash flow movement through a pyramid, tracking the propagation of exogenous shocks to different firms in the pyramidal chain. They apply their method to Indian business groups for the period 1989-1999. The results indicate significant tunneling. The authors raise the question on how groups can continue to persist if they expropriate minority shareholders. ${ }^{9}$ One possible explanation for this is because minority shareholders do not fully realize the extent of tunneling in the group (investors are myopic). However, this explanation is unconvincing as minority shareholders of firms belonging to a pyramidal chain should at least expect that the controlling family has an incentive to expropriate some part of their cash flow rights. A study done by Jian and Wong (2003) using a sample of 131 Chinese listed firms that conducted related party transactions (i.e. tunneling) shows that at least part of these transactions was indeed anticipated by the market. Evidently, investors should be reluctant in the first place to take a minority position in the firm. Even if they are willing to do so, they will obviously discount the firm's

\footnotetext{
${ }^{9}$ See also Bertrand and Mullainathan (2003).
} 
share price accordingly. Consequently, with rational investors the pyramidal ownership structure may never be superior to the horizontal structure.

Some recent papers present formal theoretical analyses of tunneling and propping. Obata (2001) presents a simple model of propping in which he describes how the pyramidal structure allows firms to be propped up in case of financial distress, if investor protection is weak. Friedman, Johnson, and Mitton (2002) also model propping, but they use a dynamic model. In that way, they can explicitly take into account the fact that an entrepreneur may want to save a firm from bankruptcy by propping, since future earnings are valuable. Propping is done by the controlling shareholder in order to revive the firm, and to preserve the possibility to carry out tunneling in the future. Both studies, however, do not consider the establishment of the ownership structure. That is, they show that if a pyramidal structure is present tunneling or propping is beneficial to the controlling shareholder. However, this does not necessarily imply that entrepreneurs will prefer the pyramidal structure over the horizontal structure. Therefore the models of Obata (2001) and Friedman, Johnson, and Mitton (2002) cannot actually compare the pyramidal and horizontal structures.

Wolfenzon (1999) presents a model of tunneling that does take into account the establishment of the ownership structure. He assumes that operating profits consist of a verifiable part plus a non-verifiable part. The verifiable profits need to be shared with the firm's other owners. However, the entrepreneur can divert (a given fraction of) the non-verifiable profits (say, an amount $s$ ) to his own pockets through self-dealing transactions. Now consider the setup of a new firm $B$ by the entrepreneur who already owns firm $A$. Regardless of the ownership structure, the entrepreneur always receives the non-verifiable cash flow $s$. Clearly, the verifiable cash flow that he receives does depend on the structure. Since to the entrepreneur it is cheaper to set up $B$ in a pyramidal structure (since then the outside investors of $A$ 
also pay part of the setup costs), he will prefer the pyramidal structure if non-verifiable profits are sufficiently large.

Wolfenzon (1999) shows that tunneling of non-verifiable funds directly to the ultimate controlling shareholder may provide a justification for the pyramidal structure. In contrast, in this paper we abstract from tunneling funds from a firm directly to the ultimate controlling shareholder (the entrepreneur or family), since this is often illegal. Instead we consider tunneling funds from one firm to another firm in the same pyramid. We do not need to resort to non-verifiable profits, instead we consider verifiable profits only.

\section{A benchmark model of tunneling}

In this section we describe and solve a simple benchmark model, focusing only on the decision of how much to tunnel. Consider the following pyramidal structure. A family owns (part of) firm $A$, which itself owns (part of) another firm, $B$. Let $\alpha$ denote the fraction of firm $A$ 's shares owned by the family, and $\beta$ the fraction of firm $B$ 's shares owned by firm $A, 0<\alpha \leq 1$ and $0<\beta \leq 1$. The family therefore has a fraction $\alpha$ of firm $A$ 's cash flow rights, and a fraction $\alpha \beta$ of firm $B$ 's cash flow rights. We assume that $\alpha$ and $\beta$ are controlling shares, i.e. using the so-called weakest-link approach ${ }^{10}$ we assume that $\min (\alpha, \beta) \geq \underline{\alpha}$ for some $\underline{\alpha}>0$ which represents the smallest possible share ownership that still enables the shareholder to exert control. From some empirical studies, values of $\underline{\alpha}$ of about $10 \%$ or $20 \%$ are reasonable. ${ }^{11}$

We have a two-period model. Firms $A$ and $B$ each undertake a project and generate a stream of cash flow of respectively $\pi_{A}>0$ and $\pi_{B}>0$, in

\footnotetext{
${ }^{10}$ In many empirical studies, the weakest link of ownership in the pyramidal chain is used as a measure of control rights (see La Porta, Lopez-de-Silanes, and Shleifer, 1999, and Claessens, Djankov, and Lang, 2000).

${ }^{11}$ See for instance La Porta, Lopez-de-Silanes, and Shleifer (1999), Claessens, Djankov and Lang (2000), and Lemmon and Lins (2003).
} 
each period, $t=1,2$. The discount factor for cash flows at $t=2$ is given by $0<\delta \leq 1$. For simplicity we assume that after $t=2$, both firms are worthless.

We assume that, since the family controls firm $A$ and thereby firm $B$, the family has a possibility to tunnel cash flow from firm $B$ to firm $A$. As we mentioned before, we assume that only tunneling in between firms within the same group or pyramid is possible (legal). The family cannot tunnel funds to their own pockets directly. Tunneling an amount $S, 0<S \leq \pi_{B}$, is modelled as taking $S$ away from firm $B$ 's cash flow at $t=1$, and 'transferring' it towards firm $A .^{12}$ Note that $S$ can be interpreted as retained earnings, i.e. a part of profits that is retained and reinvested - albeit in a different firm. The net profits after subtracting retained earnings are then distributed to shareholders as dividends according to their cash flow rights. The amount of profits and retained earnings are observable to all investors, however minority investors have no control over the choice of $S$.

The tunneled money $S$ is invested in a certain project in firm $A$ and yields an additional cash inflow of $\mu S$ at $t=2$ for firm $A$. Here, $\mu$ represents the productivity parameter of the funds reinvested, and we assume that this is the same for funds coming from firm $A$ and firm $B$. We assume that $0<\mu \leq 1 / \delta$, implying that the family has no incentive to reinvest funds from firm $A$ back into the same firm $A$. But as we will show below, for these values of the parameter $\mu$, the controlling family may indeed have an incentive to tunnel and reinvest funds from firm $B$ into firm $A$. With tunneling, the cash flow from firm $B$ at $t=1$ will be $\pi_{B}-S$ and the cash flow from firm $A$ at $t=2$ will be $\pi_{A}+S$. The family chooses $S$ at $t=1$ in order to maximize total revenues.

Tunneling is costly. Tunneling an amount $S>0$ costs $k S^{2} / 2$ at $t=1$,

\footnotetext{
${ }^{12}$ Note that if there is no threat of bankruptcy for firm $B$, it is never profitable to tunnel funds from firm $A$ to firm $B$.
} 
where $k \geq 0$ is a parameter that may, for example, depend on the quality of minority shareholder protection, that is, the quality of laws. Furthermore, we let the parameter $\tau$ to denote the maximum fraction of firm $B$ 's cash flow $\pi_{B}$ that can be tunneled to firm $A, 0<\tau \leq 1$. For example, one can imagine that some assets are hard to take away from firm $B$ in the short run. Alternatively, again, this parameter can be interpreted as describing the legal conditions. Clearly, the parameters $k$ and $\tau$ may be negatively related, but we do not model this explicitly. ${ }^{13}$

Without tunneling, the present value at $t=1$ of the family's revenues is ${ }^{14}$

$$
\Pi^{P}=\alpha(1+\delta) \pi_{A}+\alpha \beta(1+\delta) \pi_{B}
$$

where the superscript $P$ refers to the pyramidal structure. If instead the family decides to tunnel an amount $S$, which must satisfy $0<S \leq \tau \pi_{B}$, revenues are

$$
\begin{aligned}
\Pi^{P} & =\underbrace{\alpha \pi_{A}+\alpha \beta\left(\pi_{B}-S\right)}_{1 \text { st period return }}+\underbrace{\delta\left(\alpha\left(\pi_{A}+\mu S\right)+\alpha \beta \pi_{B}\right)}_{\text {2nd period return }}-k S^{2} / 2 \\
& =\alpha(1+\delta) \pi_{A}+\alpha \beta(1+\delta) \pi_{B}+\alpha(\delta \mu-\beta) S-k S^{2} / 2 .
\end{aligned}
$$

Clearly, tunneling can never be profitable if $\delta \mu<\beta$. So, $\delta \mu>\beta$ is a necessary condition for tunneling. This is intuitive: if the discounted per-dollar return is very small, you would rather have a share $\alpha \beta$ of firm $B$ 's cash flow $\left(\pi_{B}\right)$ in the first period than receiving a share $\alpha$ of the discounted return from tunneling $(\delta \mu S)$ in the second period.

More precisely, tunneling is profitable whenever

$$
f(S) \equiv \alpha(\delta \mu-\beta) S-k \frac{S^{2}}{2}>0 .
$$

\footnotetext{
${ }^{13}$ In fact, for simplicity we will drop the parameter $k$ in the later part of the paper, setting it equal to zero.

${ }^{14}$ We express the revenues in terms of their present value at $t=1$ throughout this paper for expositional convenience.
} 


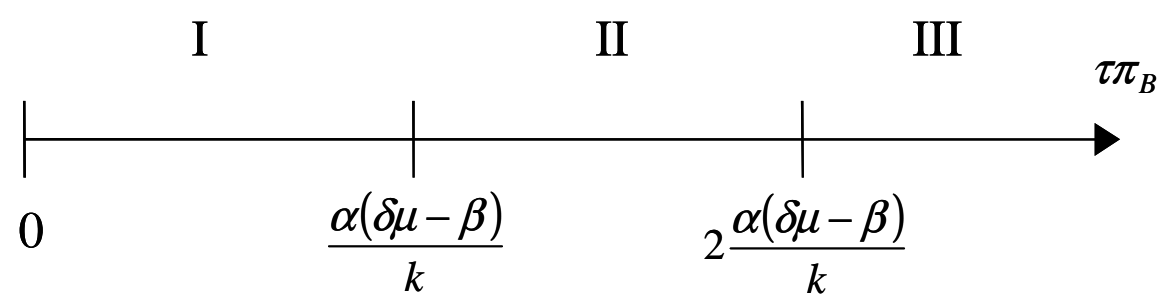

Figure 1: Critical values of the amount to be tunneled.

The optimal amount to be tunneled maximizes $f(S)$ and is given by

$$
S^{*}=\frac{\alpha(\delta \mu-\beta)}{k}
$$

whenever this expression is positive. If this exceeds $\tau \pi_{B}$, revenues are maximized by setting $S^{*}=\tau \pi_{B}$. Thus, depending on the parameter values, different situations may occur. Figure 1 illustrates the various possibilities. It shows the value of the maximum amount that may be tunneled, $\tau \pi_{B}$, together with two 'critical values'. The first one is the value of $S$ which maximizes $f(S)$; the second one corresponds to $f(S)=0$. It can be verified that tunneling the amount $\tau \pi_{B}$ is profitable if and only if $\tau \pi_{B} \leq$ $2 \alpha(\delta \mu-\beta) / k=f^{-1}(0)$. However, the amount $\alpha(\delta \mu-\beta) / k$ will instead be tunneled whenever $\tau \pi_{B}>\alpha(\delta \mu-\beta) / k$. Thus, in interval I in Figure $1, \tau \pi_{B}$ will be tunneled, whereas in intervals II and III, only $\alpha(\delta \mu-\beta) / k$ will be tunneled. Tunneling will occur in equilibrium whenever $\delta \mu>\beta$. We assume this inequality to hold. Then we have

$$
S^{*}=\min \left(\frac{\alpha(\delta \mu-\beta)}{k}, \tau \pi_{B}\right)
$$

in equilibrium. We thus have the following result.

Proposition 1 In our benchmark model of tunneling, the amount tunneled from firm $B$ to firm $A$ by the controlling family in equilibrium is higher if: 
(i) the controlling family's ownership share of firm A, $\alpha$, is greater;

(ii) the discount factor $\delta$ is greater;

(iii) the productivity of reinvested funds $\mu$ is greater;

(iv) the controlling shareholder's (firm A's) ownership share of firm B, $\beta$, is smaller;

$(v)$ tunneling is cheaper, i.e. $k$ is smaller;

(vi) the quality of legal protection of minority shareholders is worse, i.e. $\tau$ is greater;

(vii) firm $B$ 's cash flow $\pi_{B}$ is greater.

Proof. The proposition follows directly from (1).

Points $(i)$ and $(i v)$ of the above proposition illustrate the trade-off between the incentive effect and the entrenchment effect of large shareholdings. The incentive effect refers to the fact that large shareholdings help overcome the principal-agent problem; the entrenchment effect states that large investors may pursue their own interests rather than those of the firm. When $\alpha$ is high, the family tunnels more. The entrenchment effect dominates. But when the ownership stake $\beta$ of the controlling shareholder (firm $A$ ) in firm $B$ is high, the controlling family will tunnel less, and the incentive effect dominates the entrenchment effect. ${ }^{15}$

Another important implication that is worth mentioning is the impact of legal protection on tunneling. In our paper, when the quality of legal protection of

\footnotetext{
${ }^{15}$ See Claessens et al. (2002) for an empirical analysis of the tradeoff between the entrenchment and alignment effects. They show that the separation of control rights and cash flow rights brought by the pyramidal ownership structure magnifies the entrenchment effect. This is in line with our results that the controlling family may prefer the pyramidal structure.
} 
minority shareholders is good (low $\tau$ and/or high $k$ ) the pyramidal ownership structure will not lead to excessive tunneling. Assuming that investors take into account the existence of tunneling in their valuation, this implies that (lower-level) pyramidal firms should have higher market value in countries with good legal protection than their counterparts in countries with bad legal protection. ${ }^{16}$

The fact that the controlling family indeed chooses to tunnel in the equilibrium of this benchmark model suggests that when deciding on ownership structure the family may have a preference for the pyramidal structure, precisely because this enables profitable tunneling. In the remainder of this paper, we investigate this issue.

Finally, if we examine the family's revenues, it can be seen that the effect of a change in $\beta$ is ambiguous. On the one hand, an increase in $\beta$ decreases the benefit of tunneling $(\alpha(\delta \mu-\beta) S)$. On the other hand, it increases the family's share of firm $B$ 's cash flow $\left(\alpha \beta(1+\delta) \pi_{B}\right)$. A priori it is not clear which effect dominates. This implies that in the pyramidal structure, it is not always optimal for the controlling family to have the largest possible degree of separation between control rights and cash flow rights in firm $B$.

\section{Setup of the general model}

We now extend the model by incorporating the establishment of firm $B$, as well as the possibility of propping up firm $B$ when it is in financial distress. Suppose again that, initially, the family owns a controlling fraction $\alpha$ of the shares of firm $A$. At $t=0$ the family wants to set up firm $B$ either as an independent firm (horizontal structure) or as a pyramidal firm controlled by firm $A$ (pyramidal structure). That is, in the latter case, the family uses

\footnotetext{
${ }^{16}$ La Porta et al. (2002) indeed find evidence of higher valuation of large firms in countries with better protection of minority shareholders.
} 
firm $A$ to establish firm $B$. The other two periods, $t=1$ and $t=2$, are the same as before. The firms yield cash flows $\pi_{A}>0$ and $\pi_{B}>0$ in both periods (unless firm $B$ goes bankrupt, as we will explain below). There is no discounting between $t=0$ and $t=1$ for expositional convenience. This assumption does not affect the results. At $t=1$ the family decides how much of firm $B$ 's cash flow to tunnel to firm $A$. To simplify the analysis, we assume that assets are easy to transfer and hence $k=0$. Consequently the amount tunneled will only be constrained by firm $B$ 's cash flow and the quality of legal protection of minority shareholders. Thus, whenever the family finds it optimal to tunnel, she will tunnel the amount $S^{*}=\tau \pi_{B}$. Since we focus on legal tunneling and have assumed that tunneling funds directly to the family is illegal, hence if the horizontal structure is chosen tunneling is not possible. With probability $\rho, 0<\rho<1$, firm $B$ will be in financial distress in period $1{ }^{17}$ That is, firm $B$ will go bankrupt unless it is propped up. We assume that limited liability prevents the controlling shareholder from earning negative profits. This implies that the cash flow from firm $B$ in period 1 will be 0 in case of bankruptcy, rather than $\pi_{B}<0$. However, we assume that the controlling shareholder can use part of firm $A$ 's first-period cash flow $\pi_{A}$ to 'save' (prop up) firm $B$. Note that it seems reasonable to assume that since it is possible to tunnel funds from $B$ to $A$, then it is also possible to shift funds from $A$ to $B$. Under normal circumstances, the family has no incentive to do this. But if firm $B$ is in financial distress the family may find it optimal to prop firm $B$ in order to safeguard future cash flow streams. The amount of funds needed to prop up firm $B$ is exogenously given as $F>0$. If firm $B$ is propped up, it still yields a cash flow of 0 at $t=1$, but it does yield $\pi_{B}>0$ at $t=2$. As in tunneling case, we let the quality of legal protection of minority shareholders $\tau$ limits the share of a firm's cash flow that can be used to prop up another firm. That is, at most $\tau \pi_{A}$ can be used to prop up

\footnotetext{
${ }^{17}$ For expositional convenience we assume that firm $A$ will never be in financial distress.
} 
$B$.

For the pyramidal structure this implies that firm $B$ can only be saved if and only if $F \leq \tau \pi_{A}$. We will assume this condition to hold throughout the paper. After transferring the amount $F$ to firm $B$, the remainder of firm $A$ 's cash flow, $\pi_{A}-F$, will be distributed among firm $A$ 's shareholders as dividends according to their respective equity ownership of firm $A$. Thus, the controlling family and the outside investors get $\alpha\left(\pi_{A}-F\right)$ and $(1-\alpha)\left(\pi_{A}-F\right)$, respectively.

For the horizontal structure, propping up firm $B$ using funds from firm $A$ is not possible as it would imply that funds will have to be pocketed directly by the family first before they are passed to firm $A$. Recall that we assume this is illegal. However, the controlling family of course has the legal right to use its share of the cash flow obtained from firm $A$, i.e. $\alpha \pi_{A}$. Thus, the family can use this amount to prop up $B .{ }^{18}$ Clearly, in this case, the quality of legal protection $\tau$ is not binding. Obviously, propping in a horizontal structure will only be possible if $F \leq \alpha \pi_{A}$, and if propping occurs the family will end up with a cash flow of $\alpha \pi_{A}-F$ at the end of period 1 .

The establishment of firm $B$ under either structure requires an investment of size $I_{B}$. We assume that the family has no initial cash available, so in order to establish firm $B$ a fraction of firm $B$ 's equity must be sold to outside investors. ${ }^{19}$ We assume that investors have an outside option that yields a

\footnotetext{
${ }^{18} \mathrm{We}$ assume this to be legal. Note that the family may use her own funds to prop up firm $B$ in the pyramidal structure as well. That is, in the pyramidal structure, next to shifting funds up to an amount of $\tau \pi_{A}$ from $A$ to $B$, the family can also shift up to $\alpha(1-\tau) \pi_{A}$ out of her own pocket. For expositional convenience, we abstract from this. Note that including this possibility would only strengthen our results, in the sense that this makes the pyramidal structure more attractive.

${ }^{19}$ As Wolfenzon (1999) describes, the family may alternatively choose to sell both a part of firm $A$ and a part of firm $B$. The optimal fraction of each firm to sell can be determined by the maximization of the family's net expected return. In our setup, this becomes very complicated, making it impossible to compare the two structures. For that reason, we focus on the case where only a fraction of firm $B$ 's shares are sold. In a later version of
} 
net present value of zero. In the horizontal case, funds can be raised by selling a fraction $1-\beta^{H}$ of the shares of firm $B$ to outside investors, $0<\beta^{H}<1$. The remaining fraction of the shares, $\beta^{H}$, is owned by the family. In a pyramidal structure, funds can be raised by selling a fraction $1-\beta^{P}$ of the shares of firm $B$ to outside investors, $0<\beta^{P}<1$. The remaining fraction of the shares, $\beta^{P}$, is now owned by firm $A$. Note that we require the family to control not only firm $A$, but firm $B$ as well (otherwise, tunneling and propping are not possible), so using the weakest-link approach we require $\alpha \geq \underline{\alpha}$ and $\beta^{P} \geq \underline{\alpha}$ for some $\underline{\alpha}>0$. Further, we also need to verify that indeed the family wants to set up firm $B$, that is, with firm $B$ the family's net expected revenues should be greater than without it.

We continue to assume that the objective of the controlling family is to maximize revenues. However, there is now a 'budget constraint' which states that the funds raised must be at least $I_{B}$. Overall, we have a three-stage model, in which in the first stage $(t=0)$ the controlling family must choose the ownership structure and set $\beta^{H}$ or $\beta^{P}$ in order to maximize revenues subject to the budget constraint. In the second stage $(t=1)$, the family decides the amount to be tunneled from firm $B$ to firm $A$ (in the pyramidal structure only), or whether or not to prop, in case of a bankruptcy threat. In the third stage $(t=2)$ the final payoffs are realized. Figure 2 summarizes the sequence of events.

\section{Solving the model}

In this section, we discuss the solution of our general model. We solve the model using backward induction. We start with the horizontal structure. Under this structure, we distinguish two different cases: the case where propping

this paper, we hope to add an extension describing the other extreme where only a fraction of firm $A$ is sold. 


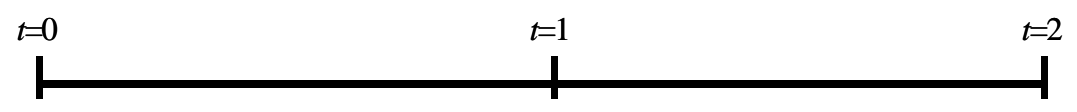

The controlling family sets up firm $B$ either as an independent firm (horizontal structure) or as a firm controlled by firm $A$ (pyramidal structure), maximizing revenues.

To finance the establishment of firm $B$ a fraction 1- $\beta$ of firm $B$ 's shares must be sold to outside investors.
The first period cash flows of firm $A\left(\pi_{A}\right)$ and firm $B$ are realized.

With probability $\rho$ firm $B$ goes bankrupt and yields 0 , and with probability $1-\rho$ firm $B$ survives and yields $\pi_{B}>0$.

The controlling family decides the amount to tunnel $(S)$ from firm $B$ to firm $A$ or the amount to prop (in order to save firm $B$ from bankruptcy). Note that in the horizontal structure $S=0$.
The second period cash flows of firm $A$ and firm $B$ $\left(\pi_{A}\right.$, and $\pi_{B}$ or 0$)$ are realized.

Payoffs to the family and outside investors are realized.

Figure 2: Sequence of events.

occurs and the case where propping does not occur. Then, we analyze the pyramidal structure. In the next section, we turn to the comparison of the two structures.

\subsection{Horizontal Structure}

\subsubsection{When propping occurs}

Notice first that in the horizontal structure, propping is possible only if $F \leq$ $\alpha \pi_{A}$ but occurs only if $F \leq \beta^{H} \delta \pi_{B}$ as well. If the latter condition is violated, it is not worthwhile to prop up firm $B$. The additional revenues from saving the firm, i.e. cash flows of $\beta^{H} \pi_{B}$ at $t=2$, do not outweigh the cost of saving firm $B$ at $t=1, F$. Thus, in the horizontal structure propping occurs in equilibrium if and only if;

$$
F \leq \min \left\{\alpha \pi_{B}, \beta^{H} \delta \pi_{B}\right\}
$$


In that case, the family's expected revenue at $t=0$ is given by

$$
\begin{aligned}
\Pi_{\mathrm{prop}}^{H}= & (1-\rho)\left(\alpha(1+\delta) \pi_{A}+\beta^{H}(1+\delta) \pi_{B}\right) \\
& +\rho\left(\alpha(1+\delta) \pi_{A}-F+\beta^{H} \delta \pi_{B}\right) \\
= & \alpha(1+\delta) \pi_{A}+\beta^{H}(1+\delta-\rho) \pi_{B}-\rho F .
\end{aligned}
$$

It is obvious that the revenue is increasing in the fraction of firm $B$ 's shares owned by the controlling family $\left(\partial \Pi_{\text {prop }}^{H} / \partial \beta^{H}>0\right)$. Hence, the controlling family will just sell enough shares to outside investors to satisfy the budget constraint with equality. ${ }^{20}$ If the family decides to sell the fraction $1-\beta^{H}$ at $t=0$ outside investors are willing to pay

$$
(1-\rho)\left(1-\beta^{H}\right)(1+\delta) \pi_{B}+\rho\left(1-\beta^{H}\right) \delta \pi_{B},
$$

taking into account that firm $B$ will be propped up in case of financial distress. Note that the maximum amount that can be raised while still enabling the controlling family to retain control over firm $B$ is $(1-\underline{\alpha})(1+\delta-\rho) \pi_{B}$. It is obvious that when the threshold of control $\underline{\alpha}$ rises, ${ }^{21}$ the maximum amount of funds that can be raised by selling part of firm $B$ 's shares decreases. Consequently, for a sufficiently high $\underline{\alpha}$ it might be possible that the amount of funds that can be raised while retaining control is not sufficient to cover the set-up costs $I_{B}$. We assume therefore that $I_{B}<(1-\underline{\alpha})(1+\delta-\rho) \pi_{B} \cdot{ }^{22}$ The controlling shareholder thus faces the following maximization problem:

$$
\begin{array}{cl} 
& \max _{\beta^{H}} \alpha(1+\delta) \pi_{A}+\beta^{H}(1+\delta-\rho) \pi_{B}-\rho F \\
\text { s.t. } & (1-\rho)\left(1-\beta^{H}\right)(1+\delta) \pi_{B}+\rho\left(1-\beta^{H}\right) \delta \pi_{B} \geq I_{B} .
\end{array}
$$

\footnotetext{
${ }^{20}$ The same argument holds for the other cases we consider below.

${ }^{21}$ The threshold $\underline{\alpha}$ is generally high in countries with concentrated ownership structure, and is low in countries with diffused ownership structure.

${ }^{22}$ We need similar assumptions for the other cases discussed below, but we do not discuss those explicitly.
} 
The value of $\beta^{H}$ that will make the budget constraint satisfied with equality is

$$
\beta_{\mathrm{prop}}^{H *}=1-\frac{I_{B}}{(1+\delta-\rho) \pi_{B}} .
$$

To ensure that indeed establishing firm $B$ is better than not establishing it we need

$$
\alpha(1+\delta) \pi_{A}+\beta_{\text {prop }}^{H *}(1+\delta-\rho) \pi_{B}-\rho F \geq \alpha(1+\delta) \pi_{A},
$$

which can be simplified into

$$
(1+\delta-\rho) \pi_{B}-\rho F \geq I_{B}
$$

This expression is intuitive, saying that the total payoffs from establishing firm $B$ under the horizontal structure with propping, net of the cost of propping and the setup costs, should be positive. Substituting (2) into the maximand yields equilibrium expected revenues equal to

$$
\Pi_{\text {prop }}^{H *}=\alpha(1+\delta) \pi_{A}+(1+\delta-\rho) \pi_{B}-\rho F-I_{B}
$$

\subsubsection{When propping does not occur}

Now, let us suppose that propping does not occur, either because the amount of funds $F$ needed is more than the amount of cash available $\left(\alpha \pi_{A}\right)$ or because propping is inefficient since $F \geq \beta^{H} \delta \pi_{B}$. The family's expected revenue at $t=0$ is now given by

$$
\begin{aligned}
\Pi_{\text {no prop }}^{H} & =(1-\rho)\left(\alpha(1+\delta) \pi_{A}+\beta^{H}(1+\delta) \pi_{B}\right)+\rho \alpha(1+\delta) \pi_{A} \\
& =\alpha(1+\delta) \pi_{A}+\beta^{H}(1-\rho)(1+\delta) \pi_{B} .
\end{aligned}
$$

Outside investors are now willing to pay an amount

$$
(1-\rho)\left(1-\beta^{H}\right)(1+\delta) \pi_{B}
$$


for a fraction $1-\beta^{H}$ of the shares of firm $B$. The controlling shareholder thus faces the following maximization problem:

$$
\begin{array}{cc}
\max _{\beta^{H}} & \alpha(1+\delta) \pi_{A}+\beta^{H}(1-\rho)(1+\delta) \pi_{B} \\
\text { s.t. } & (1-\rho)\left(1-\beta^{H}\right)(1+\delta) \pi_{B} \geq I_{B} .
\end{array}
$$

The value of $\beta^{H}$ that will make the budget constraint under the horizontal structure satisfied with equality is

$$
\beta_{\text {no prop }}^{H *}=1-\frac{I_{B}}{(1-\rho)(1+\delta) \pi_{B}} .
$$

Note that $\beta_{\text {no prop }}^{H *}$ is smaller than $\beta_{\text {prop }}^{H *}$. Since outside investors are willing to pay less per share (because now firm $B$ cannot be saved in case of financial distress) a larger part of firm $B$ needs to be sold to obtain the required amount $I_{B}$. If the following condition is satisfied establishing firm $B$ is better than not establishing it:

$$
\alpha(1+\delta) \pi_{A}+\beta^{H *}(1-\rho)(1+\delta) \pi_{B} \geq \alpha(1+\delta) \pi_{A}
$$

which can be simplified using (5) into

$$
(1-\rho)(1+\delta) \pi_{B} \geq I_{B}
$$

This expression says that the total (net) payoffs from establishing firm $B$ under the horizontal structure without propping should be positive. Using (5) equilibrium expected revenues are

$$
\Pi_{\text {no prop }}^{H *}=\alpha(1+\delta) \pi_{A}+(1-\rho)(1+\delta) \pi_{B}-I_{B}
$$

\subsection{Pyramidal Structure}

Now we turn to the pyramidal structure. Borrowing from our earlier results, the optimal amount to be tunneled by the controlling family is $S^{*}=\tau \pi_{B}$ 
because $k=0$. Propping is possible only if $F \leq \tau \pi_{A}$ which we assume to hold, but occurs only if $F \leq \beta^{P} \delta \pi_{B}$ as well. Below, we assume this to be satisfied. Then at $t=0$ the family's expected revenue is

$$
\begin{aligned}
\Pi^{P}= & (1-\rho)\left(\alpha(1+\delta) \pi_{A}+\alpha \beta^{P}(1+\delta) \pi_{B}+\alpha\left(\delta \mu-\beta^{P}\right) \tau \pi_{B}\right) \\
& +\rho\left(\alpha\left((1+\delta) \pi_{A}-F\right)+\alpha \beta^{P} \delta \pi_{B}\right) \\
= & \alpha(1+\delta) \pi_{A}+\alpha \beta^{P}(1+\delta-\rho) \pi_{B}+(1-\rho) \alpha\left(\delta \mu-\beta^{P}\right) \tau \pi_{B}-\rho \alpha F .
\end{aligned}
$$

Note that the difference with respect to propping as compared to the horizontal case is that now, $F$ is multiplied by $\alpha$. That is, the outside investors carry part of the burden of propping up $B$. For a fraction $1-\beta^{P}$ of firm $B$ outside investors are willing to pay

$$
(1-\rho)\left(1-\beta^{P}\right)(1+\delta-\tau) \pi_{B}+\rho\left(1-\beta^{P}\right) \delta \pi_{B}
$$

We assume here that investors can discern the extent of tunneling and will take it into account in their investment decision. This lowers the amount of money that can be raised by the family.

The family thus faces the following maximization problem:

$$
\begin{array}{cl}
\max _{\beta^{P}} & \alpha(1+\delta) \pi_{A}+\alpha \beta^{P}(1+\delta-\rho) \pi_{B}+(1-\rho) \alpha\left(\delta \mu-\beta^{P}\right) \tau \pi_{B}-\rho \alpha F \\
& \text { s.t. } \quad(1-\rho)\left(1-\beta^{P}\right)(1+\delta-\tau) \pi_{B}+\rho\left(1-\beta^{P}\right) \delta \pi_{B} \geq I_{B} .
\end{array}
$$

The value of $\beta^{P}$ that will make the budget constraint satisfied with equality is

$$
\beta^{P *}=1-\frac{I_{B}}{(1+\delta-\rho-(1-\rho) \tau) \pi_{B}} .
$$

For the family's revenue with firm $B$ to exceed the revenue without firm $B$ we require

$$
\begin{aligned}
& \alpha(1+\delta) \pi_{A}+\alpha \beta^{P *}(1+\delta-\rho) \pi_{B}+(1-\rho) \alpha\left(\delta \mu-\beta^{P *}\right) \tau \pi_{B}-\rho \alpha F \\
\geq & \alpha(1+\delta) \pi_{A} .
\end{aligned}
$$


Using (9) we can simplify this into

$$
(1+\delta-\rho-(1-\rho)(1-\delta \mu) \tau) \pi_{B}-\rho F \geq I_{B}
$$

This expression says that the total payoffs from establishing firm $B$ under the horizontal structure with propping, net of the cost of propping, tunneling, and the setup costs, should be positive. It is obvious that when the probability of bankruptcy is zero, $\rho=0$, and thus there is only tunneling and no propping, the above expression reduces to

$$
(1+\delta-(1-\delta \mu) \tau) \pi_{B} \geq I_{B}
$$

Finally, using (9), equilibrium payoffs under the pyramidal structure can be rewritten as

$$
\Pi^{P *}=\alpha(1+\delta) \pi_{A}+(1+\delta-\rho-(1-\rho)(1-\delta \mu) \tau) \alpha \pi_{B}-\rho \alpha F-\alpha I_{B} .
$$

\section{Pyramidal structure versus horizontal struc- ture}

At $t=0$, the controlling family must decide under which ownership structure firm $B$ will be established. For this, we investigate which structure yields the highest revenue to the family. We will first consider a case in which only tunneling is present and examine whether tunneling alone is enough to justify the emergence of a pyramidal ownership structure. Then, we turn to the case where propping does occur.

\subsection{Can tunneling alone justify pyramidal ownership?}

Since in our model by assumption tunneling is possible (legal) only in the pyramidal ownership structure, and since the family does indeed use tunneling if this structure is present, one might expect tunneling to be one of the 
reasons to choose the pyramidal ownership structure in the first place. In this subsection, we analyze this issue. Does tunneling alone (in the absence of propping) provide a justification for pyramidal ownership? In order to answer this question, we let the probability of bankruptcy of firm $B, \rho$, equals to zero for now.

Proposition 2 In our model with tunneling only $(\rho=0)$ the pyramidal structure can never be strictly preferred over the horizontal structure.

Proof. See appendix.

This implies that tunneling cannot be the sole reason for the controlling family to choose the pyramidal ownership structure. The reason why the pyramidal ownership structure cannot be optimal under the tunneling-only case is that when firm $B$ is established outside investors anticipate that there will be tunneling and thus take it into account in their investment decision, i.e. in their willingness to pay for B's shares (8) (as suggested by Bertrand, Mehta, and Mullainathan, 2002, p. 146).

If outside investors do not realize the full extent of the tunneling by the controlling family (i.e. if they use some $\tau^{\prime}<\tau$ in their calculations) then it can be shown that under some conditions the pyramidal structure can indeed be optimal. To illustrate this consider the following modification of the model. Suppose that investors are myopic. For simplicity, we assume that investors completely ignore the possibility of tunneling, that is, they believe that the amount tunneled is 0 . Hence, the budget constraint of the controlling family is $\left(1-\beta^{P}\right)(1+\delta) \pi_{B} \geq I_{B}$. We can rewrite the maximization problem of the controlling family, substituting $\rho=0$, as

$$
\begin{gathered}
\max _{\beta^{P}} \alpha(1+\delta) \pi_{A}+\alpha \beta^{P}(1+\delta) \pi_{B}+\alpha\left(\delta \mu-\beta^{P}\right) \tau \pi_{B} \\
\text { s.t. } \quad\left(1-\beta^{P}\right)(1+\delta) \pi_{B} \geq I_{B} .
\end{gathered}
$$


The value of $\beta^{P}$ that will make the budget constraint under the horizontal structure satisfied with equality is

$$
\beta_{\mathrm{myopic}}^{P *}=1-\frac{I_{B}}{(1+\delta) \pi_{B}} .
$$

Again we need the revenue with firm $B$ to exceed the revenue without firm $B$,

$$
\alpha(1+\delta) \pi_{A}+\alpha \beta_{\text {myopic }}^{P *}(1+\delta) \pi_{B}+\alpha\left(\delta \mu-\beta_{\text {myopic }}^{P *}\right) \tau \pi_{B} \geq \alpha(1+\delta) \pi_{A}
$$

Using (13) we can further simplify this into

$$
\frac{1+\delta}{1+\delta-\tau}(1+\delta-(1-\delta \mu) \tau) \pi_{B} \geq I_{B}
$$

Using(13), equilibrium payoffs can be rewritten as

$$
\Pi_{\mathrm{myopic}}^{P *}=\alpha(1+\delta) \pi_{A}+\alpha(1+\delta-(1-\delta \mu) \tau) \pi_{B}-\frac{1+\delta-\tau}{1+\delta} \alpha I_{B}
$$

Upon comparing this revenue to that of the horizontal structure (in the absence of propping), we can establish the following proposition.

Proposition 3 In our model with tunneling only $(\rho=0)$, if investors are myopic and do not take tunneling into account in their investment decision, then the pyramidal structure can be strictly preferred over the horizontal structure.

Proof. See appendix.

Thus, the possibility of tunneling (only) can lead to the emergence of the pyramidal structure if and only if investors do not (fully) realize the extent of tunneling, that is, if investors are myopic. Admittedly, in the above analysis we have used an extreme assumption - that investors do not take tunneling 
into account at all. This seems to contradict 'the stock price evidence $[\ldots]$ which suggests that markets at least partly understand the extent of tunneling' (Bertrand and Mullainathan, 2003, p. 481). However, it can easily be verified that our result continues to hold if investors do realize that there will be tunneling, but underestimate the extent of it. We can thus conclude that having to resort to the assumption of myopic investors to justify the existence of pyramidal ownership structures is not very satisfying. For that reason, we now return to our general model where investors are fully rational, and consider propping in addition to tunneling as a justification for the pyramidal structure.

\subsection{The choice of structure in the general model}

Now we return to the general model, in which both tunneling and propping may occur. First, let us consider the case in which the parameters of the model are such that propping occurs in both the horizontal structure and the pyramidal structure. Thus, we assume that $F \leq \min \left\{\alpha \pi_{A}, \beta_{\text {prop }}^{H *} \delta \pi_{B}\right\}$ and $F \leq \min \left\{\tau \pi_{A}, \beta^{P *} \delta \pi_{B}\right\} \cdot{ }^{23}$ As before, we compare the family's revenue under the two structures.

Proposition 4 In our model, if propping occurs in both structures, then the pyramidal structure can never be strictly preferred over the horizontal structure.

Proof. See appendix.

Although propping up firm $B$ is cheaper to the family in the pyramidal structure (since outside investors share in the burden), to outside investors the only difference between the two structures is the tunneling. As we explained

\footnotetext{
${ }^{23}$ Abstracting from corner solutions.
} 
above, they take this into account in their investment decision. So, again, the pyramidal structure cannot yield higher revenues to the family.

Now suppose that propping cannot be done in the horizontal structure because the amount of funds needed to save firm $B$ exceeds the total cash flow rights of the controlling family in firm $A, F>\alpha \pi_{A}{ }^{24}$ We continue to assume that propping is possible in the pyramidal structure, that is, $F \leq \min \left\{\tau \pi_{A}, \beta^{P *} \delta \pi_{B}\right\}$ (for example because $\pi_{B}$ is relatively large). Comparing the controlling family's revenue under the two structures we can establish the following proposition.

Proposition 5 In our model, if propping occurs only in the pyramidal structure but not in the horizontal structure, then the pyramidal structure can be strictly preferred over the horizontal structure.

Proof. See appendix.

Our analysis shows that even though investors fully realize that there will be tunneling in the pyramidal structure, they are still willing to invest a relatively large amount because they know that propping is possible in this structure. With propping firm $B$ can be saved from bankruptcy, which is good for investors. The presence of propping acts as a kind of insurance for minority investors. They are willing to be expropriated to some extent in exchange for the larger probability of realizing positive returns from their investment in the future. One can consider the expropriation by the controlling family as a kind of insurance premium that has to be paid by minority shareholders. Thus, since in the horizontal structure the extent of propping

\footnotetext{
${ }^{24}$ Alternatively, we could assume that propping in the horizontal structure is feasible, but not efficient from the point of view of the family, i.e. $\beta_{\text {prop }}^{H *} \delta \pi_{B}<F \leq \alpha \pi_{A}$. However, to analyze this situation in detail we would have to study corner solutions as well, where the firm chooses another $\beta$ which just allows for propping. We choose to abstract from this, and focus on the case where propping is simply not possible.
} 
is limited by the amount of funds the family has available, it is possible that propping cannot be done under the horizontal structure whereas it can under the pyramidal structure. When this is the case, the pyramidal structure is optimal for the controlling family.

\section{Conclusion}

This paper presented a model of tunneling and propping in a pyramidal ownership structure. We first considered an environment in which only tunneling is present, and then introduced propping into the framework. The focus of the paper is to investigate whether or not tunneling and/or propping can justify the emergence of pyramids. That is, we asked whether a controlling family who is going to establish a new firm would prefer to establish the firm in a pyramidal or a horizontal ownership structure.

We have focused on the type of tunneling that is often considered legal, i.e. where funds are tunneled from one firm to another firm in the same pyramid or business group. We have abstracted from tunneling funds from a firm directly to the family's pockets, as this would be similar to the family simply donating all the firm's cash flow to herself as the ultimate controlling shareholder rather than paying out dividends according to all investor's cash flow rights.

We showed that tunneling alone cannot lead to the emergence of the pyramidal ownership structure. The reason is that rational minority investors of the new lower-level firm will take the tunneling into account in their investment decision, i.e. in their willingness to pay. As a result, the pyramidal ownership structure can never be strictly preferred by the controlling family (even though, once the pyramidal structure is in place, they find tunneling profitable). However, we also show that if investors are myopic and do not 
foresee that there will be tunneling or underestimate the degree of tunneling, then the pyramidal ownership structure may be optimal.

Given that - with rational investors - tunneling cannot be the sole reason for the emergence of the pyramidal ownership structure, we explore another closely related phenomenon that may play a role in the choice of ownership structure. We incorporate propping into the framework. We interpret propping as 'reverse' tunneling, where funds flow from the old, higher-level firm to the new, lower-level firm in the same pyramid, which is done to save the latter firm from bankruptcy. We show that when there is some positive probability of bankruptcy and the controlling family is able to save the new firm from bankruptcy by propping in the pyramidal ownership structure, this structure can indeed be preferred over the horizontal structure. The reason is that even though investors expect that there will be tunneling in the pyramidal structure, they are still willing to invest a relatively large amount because they know that propping is possible. With propping, firm the new firm $B$ can be saved from a bankruptcy, so propping acts as a kind of insurance for these minority investors. They are willing to be expropriated to some extent (by tunneling) in exchange for the increased probability of realizing positive returns from their investment in the future.

Of course, in the horizontal structure the family might also be able to prop up firm $B$, now using their own funds (in our model, their share of the old firm's cash flow) rather than the old firm's funds. But as we show using our model, depending on the values of the parameters, the family may well have less funds available for propping than the old firm has and therefore propping may be possible in the pyramidal structure but not in the horizontal structure. Note that the family may use her own funds to prop up firm $B$ in the pyramidal structure as well. Including this possibility would only strengthen our results, in the sense that this makes the pyramidal structure more attractive. 
We have abstracted from the possibility that the old firm itself may go bankrupt. Our model could be extended by adding a positive probability for this firm to be in financial distress and to go bankrupt unless it is propped up. However, we do not expect this to affect our qualitative results. In our current setup, in the pyramidal structure funds will be tunneled from the lower-level firm $B$ to the old, higher-level firm $A$ for some parameter values. By introducing the possibility of bankruptcy of firm $A$, funds will move in this direction for a wider range of parameters. Just like before, outside investors will take this into account (unless they are myopic).

With respect to the amount of money that is needed to prop up the firm in case of financial distress, we have focused on an exogenously given amount. However, in general this amount will not be given but rather be distributed according to some probability distribution function. In that case, our result will still hold, provided that the probability of being in the relevant interval is sufficiently large.

Summarizing, depending on the values of the parameters tunneling may justify the pyramidal structure, but only with myopic investors or in combination with propping to save the new, lower-level firm from bankruptcy.

\section{Appendix}

\section{Proof of Proposition 2}

With tunneling only $(\rho=0)$, the pyramidal structure is strictly preferred over the horizontal structure if and only if, substituting $\rho=0, \Delta=\Pi^{P *}-$ $\Pi_{\text {no prop }}^{H *}>0$. Using $(7)$ and (12) and taking into account that $\rho=0$, we can simplify the above expression into

$$
\Delta=(1-\alpha) I_{B}-(1-\alpha)(1+\delta) \pi_{B}-\alpha(1-\delta \mu) \tau \pi_{B}>0
$$


which is equivalent to the following condition:

$$
(1+\delta) \pi_{B}+\frac{\alpha}{1-\alpha}(1-\delta \mu) \tau \pi_{B}<I_{B}
$$

We should also make sure that the feasibility conditions (6) and (11) are satisfied. Substituting $\rho=0$, we can simplify these feasibility conditions into

$$
\begin{aligned}
(1+\delta) \pi_{B} & \geq I_{B} \\
(1+\delta-(1-\delta \mu) \tau) \pi_{B} & \geq I_{B} .
\end{aligned}
$$

It can be seen that the second condition is stricter than the first one, so we can focus on the second condition. Thus, the pyramidal structure is strictly preferred over the horizontal structure when both this condition and the condition $\Delta>0$ hold. That would require

$$
(1+\delta) \pi_{B}+\frac{\alpha}{1-\alpha}(1-\delta \mu) \tau \pi_{B}<(1+\delta) \pi_{B}-(1-\delta \mu) \tau \pi_{B}
$$

that is $\frac{\alpha}{1-\alpha}<-1$. Clearly this is impossible because $\frac{\alpha}{1-\alpha}>0$.

\section{Proof of Proposition 3}

With tunneling only $(\rho=0)$ and myopic investors who do not take tunneling into account, the pyramidal structure is strictly preferred over the horizontal structure if and only if, substituting $\rho=0, \Delta=\Pi_{\text {myopic }}^{P *}-\Pi_{\text {no prop }}^{H *}>0$. Using (7) and (15) and taking into account that $\rho=0$, we can simplify the above expression into

$$
\Delta=\left(1-\frac{1+\delta-\tau}{1+\delta} \alpha\right) I_{B}-(1-\alpha)(1+\delta) \pi_{B}-(1-\delta \mu) \alpha \tau \pi_{B}>0
$$

which is equivalent to the following condition:

$$
(1+\delta)\left(1-\frac{\alpha \tau \delta \mu}{(1+\delta)(1-\alpha)+\alpha \tau}\right) \pi_{B}<I_{B}
$$


The feasibility conditions (6) and (14) can be rewritten as

$$
\begin{aligned}
(1+\delta) \pi_{B} & \geq I_{B} \\
\frac{1+\delta}{1+\delta-\tau}(1+\delta-(1-\delta \mu) \tau) \pi_{B} & \geq I_{B} .
\end{aligned}
$$

It can be verified that the first condition is stricter than the second one, so we can focus on the first condition. Thus, the pyramidal structure is strictly preferred over the horizontal condition when both this condition and the condition $\Delta>0$ hold. For these two conditions to be satisfied simultaneously, we require

$$
(1+\delta)\left(1-\frac{\alpha \tau \delta \mu}{(1+\delta)(1-\alpha)+\alpha \tau}\right) \pi_{B}<(1+\delta) \pi_{B}
$$

that is $\frac{\alpha \tau \delta \mu}{(1+\delta)(1-\alpha)+\alpha \tau}>0$. This condition is satisfied for all feasible values of $\alpha, \tau, \delta$, and $\mu$. Thus, the pyramidal structure may be strictly preferred over the horizontal structure in this case.

\section{Proof of Proposition 4}

With propping in both structures, the pyramidal structure is strictly preferred over the horizontal structure if and only if $\Delta=\Pi^{P *}-\Pi_{\text {prop }}^{H *}>0$, which can be expressed as

$$
\begin{aligned}
\Delta & =(1-\alpha) I_{B}+(1-\alpha) \rho F \\
& -(1-\alpha)(1+\delta-\rho) \pi_{B}-\alpha(1-\rho)(1-\delta \mu) \tau \pi_{B}>0 .
\end{aligned}
$$

using (4) and (12). This expression can be rewritten as

$$
(1+\delta-\rho) \pi_{B}+\frac{\alpha}{1-\alpha}(1-\rho)(1-\delta \mu) \tau \pi_{B}-\rho F<I_{B}
$$

From (3) and (10) the feasibility conditions are

$$
\begin{aligned}
(1+\delta-\rho) \pi_{B}-\rho F & \geq I_{B}, \\
(1+\delta-\rho) \pi_{B}-(1-\rho)(1-\delta \mu) \tau \pi_{B}-\rho F & \geq I_{B} .
\end{aligned}
$$


The second condition is stricter than the first one, so we can focus on the second condition. Thus, the pyramidal structure is strictly preferred over the horizontal structure when both this condition and the condition $\Delta>0$ hold. For these two conditions to be satisfied simultaneously, we require

$$
\begin{aligned}
& (1+\delta-\rho) \pi_{B}+\frac{\alpha}{1-\alpha}(1-\rho)(1-\delta \mu) \tau \pi_{B}-\rho F \\
< & (1+\delta-\rho) \pi_{B}-(1-\rho)(1-\delta \mu) \tau \pi_{B}-\rho F
\end{aligned}
$$

that is, $\frac{\alpha}{1-\alpha}<-1$. Clearly this can never be satisfied because $\frac{\alpha}{1-\alpha}>0$.

\section{Proof of Proposition 5}

With propping in the pyramidal structure only, the pyramidal structure is strictly preferred over the horizontal structure if and only if $\Delta=\Pi^{P *}-$ $\Pi_{\text {no prop }}^{H *}>0$, which can be expressed as

$$
\begin{aligned}
\Delta & =(1-\alpha) I_{B}-\rho \alpha F-(1-\alpha)(1+\delta-\rho) \pi_{B} \\
& +\rho \delta \pi_{B}-\alpha(1-\rho)(1-\delta \mu) \tau \pi_{B}>0
\end{aligned}
$$

using (7) and (12). This expression can be rewritten as

$$
(1+\delta-\rho) \pi_{B}-\frac{1}{1-\alpha} \rho \delta \pi_{B}+\frac{\alpha}{1-\alpha}(1-\rho)(1-\delta \mu) \tau \pi_{B}+\frac{\alpha}{1-\alpha} \rho F<I_{B} .
$$

From (6) and (10) the feasibility conditions are

$$
\begin{aligned}
(1-\rho)(1+\delta) \pi_{B} & \geq I_{B}, \\
(1+\delta-\rho) \pi_{B}-(1-\rho)(1-\delta \mu) \tau \pi_{B}-\rho F & \geq I_{B} .
\end{aligned}
$$

It is not clear beforehand which condition is more restrictive. Therefore, we consider two cases. 
First assume that the first feasibility condition is more restrictive. Then the pyramidal structure is strictly preferred over the horizontal structure when both this condition and the condition $\Delta>0$ hold. This requires

$$
\begin{aligned}
& (1+\delta-\rho) \pi_{B}-\frac{1}{1-\alpha} \rho \delta \pi_{B}+\frac{\alpha}{1-\alpha}(1-\rho)(1-\delta \mu) \tau \pi_{B}+\frac{\alpha}{1-\alpha} \rho F \\
< & (1-\rho)(1+\delta) \pi_{B}
\end{aligned}
$$

which can be rewritten as

$$
(1-\rho)(1-\delta \mu) \tau \pi_{B}-\rho \delta \pi_{B}+\rho F<0
$$

It can easily be verified that the condition for the first feasibility condition to be more strict than the second reduces to precisely this expression. That is, whenever the first feasibility condition is more strict, this expression holds true, and the pyramidal structure may dominate (depending on the values of other parameters).

Second, assume that the second feasibility condition is more restrictive. Then the pyramidal structure is strictly preferred over the horizontal structure when both this condition and the condition $\Delta>0$ hold. This requires

$$
\begin{aligned}
& (1+\delta-\rho) \pi_{B}-\frac{1}{1-\alpha} \rho \delta \pi_{B}+\frac{\alpha}{1-\alpha}(1-\rho)(1-\delta \mu) \tau \pi_{B}+\frac{\alpha}{1-\alpha} \rho F \\
< & (1+\delta-\rho) \pi_{B}-(1-\rho)(1-\delta \mu) \tau \pi_{B}-\rho F
\end{aligned}
$$

which can be simplified into precisely the same condition as before, (17). Clearly, if the second feasibility condition is more restrictive the pyramidal structure can thus never be preferred over the horizontal structure.

Combining, the pyramidal structure dominates in this situation if and only if the first feasibility condition is more restrictive than the second. That is, if (17) holds. To illustrate that this may indeed occur at least for some parameter values, consider the following example. Let $\delta=\mu=\tau=1$, $\rho=0.5, \alpha=0.8, \pi_{A}=7, \pi_{B}=10, I_{B}=4, F=6$. It can easily be verified 
that (17) is satisfied for these parameter values. Also, it can easily be seen that the other conditions that we require for this case (with propping in the pyramidal structure only), i.e. that $\alpha \pi_{A}<F \leq \min \left\{\tau \pi_{A}, \beta^{P *} \delta \pi_{B}\right\}$, where $\beta^{P *}=0.6$ now, are satisfied. Finally, we have $\Delta=\frac{2}{5}>0$. Thus, indeed, in this example the case with propping in the pyramidal structure only is the relevant case, setting up firm $B$ in either structure is feasible, and the pyramidal structure dominates.

\section{References}

BAE, K.-H., J.-K. KAnG, And J.-M. KIM (2002): "Tunneling or Value Added? Evidence from Mergers by Korean Business Groups," Journal of Finance, 57(6), 2695-2740.

Berle, A. A., and G. C. Means (1932): The Modern Corporation and Private Property. MacMillan, New York.

Bertrand, M., P. Mehta, and S. Mullainathan (2002): "Ferreting Out Tunneling: An Application to Indian Business Groups," Quarterly Journal of Economics, 117(1), 121-148.

Bertrand, M., and S. Mullainathan (2003): "Pyramids," Journal of the European Economic Association, 1(2-3), 478-483.

Clatessens, S., S. Djankov, J. P. Fan, and L. H. Lang (2002): "Disentangling the Incentive and Entrenchment Effects of Large Shareholdings," Journal of Finance, 57(6), 2741-2771.

Claessens, S., S. Duankov, and L. H. Lang (2000): "The Separation of Ownership and Control in East Asian Corporations," Journal of Financial Economics, 58(1-2), 81-112. 
Friedman, E., S. Johnson, And T. Mitton (2003): "Propping and Tunnelling," Journal of Comparative Economics, 31(4), 732-750.

JiAn, M., And T. Wong (2003): "Earnings Management and Tunneling Through Related Party Transactions: Evidence from Chinese Corporate Groups," mimeo, Hong Kong University of Science and Technology.

Johnson, S., R. La Porta, F. Lopez-De-Silanes, and A. Shleifer (2000): "Tunnelling," American Economic Review, 90(2), 22-27.

La Porta, R., F. Lopez-De-Silanes, and A. Shleifer (1999): “Corporate Ownership Around the World," Journal of Finance, 54(2), 471-517.

La Porta, R., F. Lopez-De-Silanes, A. Shleifer, and R. Vishny (2002): "Investor Protection and Corporate Valuation," Journal of Finance, 57(3), 1147-1170.

Lemmon, M. L., And K. V. Lins (2003): "Ownership Structure, Corporate Governance, and Firm Value: Evidence from the East Asian Financial Crisis," Journal of Finance, 58(4), 1445-1468.

ObAtA, S. (2001): "Pyramid Groups, Financial Distress and Investor Protection," mimeo, Harvard University, Cambridge, Mass.

Shleifer, A., And R. W. Vishny (1997): "A Survey of Corporate Governance," Journal of Finance, 52(2), 737-783.

The Economist (2004): "Parma Splat," January 27.

Wolfenzon, D. (1999): "A Theory of Pyramidal Ownership," mimeo, University of Michigan Business School, Ann Arbor, Michigan. 